\title{
Histopathological Characteristics of Hepatic Lipogranulomas with Portosystemic Shunt in Dogs
}

\author{
Kaori ISOBE ${ }^{1)}$, Satoru MATSUNAGA ${ }^{2)}$, Hiroyuki NAKAYAMA ${ }^{1)}$ and Koji UETSUKA ${ }^{1) *}$ \\ ${ }^{1)}$ Departments of Veterinary Pathology and ${ }^{2)}$ Veterinary Emergency Medicine, Graduate School of Agricultural and Life Sciences, The \\ University of Tokyo, 1-1-1 Yayoi, Bunkyo-ku, Tokyo 113-8657, Japan
}

(Received 23 May 2007/Accepted 26 September 2007)

\begin{abstract}
In the canine liver with portosystemic shunts (PSS), focal lesions consisting of cells with cytoplasmic brown pigments and lipid vacuoles are often observed in the hepatic parenchyma. Termed lipogranulomas, their histopathological characteristics have been little studied. In the present study, we examined liver biopsy samples from 144 dogs (age: 3 months-16 years; 65 PSS and 79 non-PSS cases), and investigated the histopathological characteristics, incidence, and density of lipogranulomas. Lipogranulomas were detected histopathologically in $55.4 \%$ of PSS dogs. The lesions were then grouped into 3 types according to the amount of cytoplasmic lipid vacuoles and brown pigments. The pigments were positive for Berlin blue, PAS, and Sudan black B, but negative with the Hall method. The majority of the cells were immunohistochemically positive for macrophage scavenger receptor, class A (MSR-A), while no cells were positive for hepatocyte-antigen and albumin. The cytoplasmic pigments were recognized as electron-dense microgranular materials by electron microscopy. The incidence of lipogranulomas was significantly higher in the PSS group than non-PSS group when dogs less than 1 year old were excluded. The lipogranuloma density in the liver was significantly higher in the PSS group. It is concluded that lipogranulomas are frequently observed in liver biopsies of canine PSS especially in dogs more than 1 year old. The lesions consisted of Kupffer cells and/or macrophages, and the cytoplasmic brown pigments are ceroid and hemosiderin. The pathogenesis of lipogranuloma in PSS needs to be clarified.
\end{abstract}

KEY WORDS: canine, lipogranuloma, liver, phagocytes, portosystemic shunt.

J. Vet. Med. Sci. 70(2): 133-138, 2008

Portosystemic shunts (PSS) are defined as "anomalous vessels that allow normal portal blood draining from the stomach, intestines, pancreas, and spleen to pass directly into the systemic circulation without first passing through the liver [8]". When portal blood bypasses the liver, essential hepatotrophic substances from the pancreas and intestines do not reach the liver, resulting in hepatic atrophy [8]. It is well known that PSS occur in dogs [4]. The histopathology of canine livers with PSS is characterized by arteriolar proliferation, hepatocytic vacuolization, biliary hyperplasia, mild periportal fibrosis, and foci of iron rich fatty macrophages (lipogranulomas) [4].

Lipogranulomas, also termed fatty cysts, are often found in the hepatic parenchyma of dogs with PSS $[2,4,15,16]$. There are several descriptions of the lesions in the canine liver with various pathological conditions including PSS $[13,21]$. As far as we know, however, there are no reports of a morphometric analysis examining whether the incidence of lipogranulomas in the canine PSS liver is indeed higher than that in non-PSS cases, and the histopathological characteristics of lipogranulomas with PSS have not been examined in detail.

In the present study, we therefore examined the occurrence and histopathological characteristics of lipogranulomas in the livers of canines with PSS.

\footnotetext{
* Correspondence to: Uetsuka, K., Department of Veterinary Pathology, Graduate School of Agricultural and Life Sciences, The University of Tokyo, 1-1-1 Yayoi, Bunkyo-ku, Tokyo 1138657, Japan.

e-mail: akasata@mail.ecc.u-tokyo.ac.jp
}

\section{MATERIALS AND METHODS}

Samples: Liver samples were obtained from 144 dogs (3 months to 16 years of age) at the Veterinary Medical Center, the University of Tokyo between January 2003 and May 2006. They were divided into 2 groups, PSS (65 cases) and non-PSS (79 cases), according to the clinical data.

Histopathological examination: Liver tissues were fixed in $10 \%$ neutral-buffered formalin, embedded in paraffin, and sectioned $4 \mu \mathrm{m}$ thick. The paraffin sections were stained with hematoxylin and eosin (HE). For further histopathological examination of lipogranulomas, special stains, such as Berlin blue, the Hall method, the Periodic acid/ Schiff (PAS) reaction, and Sudan black B, and immunostains were used in 21 samples of PSS.

For immunostaining, deparaffinized sections were autoclaved or digested in $0.1 \%$ trypsin for antigen retrieval, and then immersed in $0.3 \%$ hydrogen peroxidase to block internal peroxidase activity, and in $8 \%$ skim milk to block nonspecific binding of the primary antibody. Primary antibodies (Table 1) were applied to the section. The sections were then reacted with each biotinylated secondary antibody (KPL, Gaithersburg, MD, U.S.A.), incubated with peroxidase-labeled streptavidin (Dako, Glostrup, Denmark), and visualized with 3,3'-diaminobenzidine-tetrahydrochloride (DAB) as chromogen. In order to clearly distinguish the positive reaction from cytoplasmic brown pigments in lipogranulomas, the reaction color was changed to bluish purple with $\mathrm{NiCl}_{2}$-DAB $[12,14]$. Counterstaining was done with methyl green. 
Table 1. Primary antibodies used

\begin{tabular}{|c|c|c|c|c|c|}
\hline Antigen & $\begin{array}{l}\text { Antigen-derived } \\
\text { animal }\end{array}$ & Clone & Dilution & Pretreatment & Manufacturer \\
\hline Lysozyme & Human & - & $1: 200$ & Trypsin digested & $\begin{array}{l}\text { Dako, Glostrup, } \\
\text { Denmark }\end{array}$ \\
\hline $\begin{array}{l}\text { Macrophage scavenger } \\
\text { receptor, class A (MSR-A) }\end{array}$ & Human & SRA-E5 & $1: 25$ & Autoclaved & $\begin{array}{l}\text { Trans Genic Inc., } \\
\text { Kobe, Japan }\end{array}$ \\
\hline Desmin & - & - & $1: 200$ & Autoclaved & $\begin{array}{l}\text { Dako, Glostrup, } \\
\text { Denmark }\end{array}$ \\
\hline $\begin{array}{l}\alpha \text {-smooth muscle actin } \\
(\alpha \text {-SMA) }\end{array}$ & Human & $1 \mathrm{~A} 4$ & $1: 50$ & Autoclaved & $\begin{array}{l}\text { Dako, Glostrup, } \\
\text { Denmark }\end{array}$ \\
\hline Albumin & Dog & - & $1: 200$ & Trypsin digested & $\begin{array}{l}\text { Bethyl, Labo., INC, } \\
\text { TX, U.S.A. }\end{array}$ \\
\hline Hepatocyte & Human & OCH1E5 & $1: 25$ & Autoclaved & $\begin{array}{l}\text { Dako, Glostrup, } \\
\text { Denmark }\end{array}$ \\
\hline
\end{tabular}

Electron microscopy: Liver tissue samples were cut into small blocks, and refixed in $2.5 \%$ glutaraldehyde for $3 \mathrm{hr}$ and $1 \%$ osmium tetroxide for $2.5 \mathrm{hr}$, respectively. Then, they were dehydrated through a graded alcohol series $(50 \%$, $70 \%, 80 \%, 90 \%, 95 \%$ and $100 \%$ ) and propylene oxide, and embedded in Epon 812. Ultrathin sections were prepared using a ultramicrotome, double-stained with uranyl acetate and lead citrate, and examined under a transmission electron microscope, JEM 1200 (JEOL Ltd, Tokyo, Japan) at $80 \mathrm{kV}$.

Density of lipogranulomas: The number of lipogranulomas was counted on 3 images $(3,200 \times 2,560$ pixels $)$ taken from each $\mathrm{HE}$ section with $\mathrm{a} \times 10$ objective lens. The total number of lipogranulomas in the 3 images was considered to be the lipogranuloma density per a definite area.

Statistical methods: The chi-square test was used for comparison of the incidence and density of lipogranulomas between the PSS and non-PSS groups. $P$ values less than 0.01 were considered significant.

\section{RESULTS}

Thirty nine liver biopsy samples of dogs with PSS obtained between 2004 and 2005 were histopathologically examined. Among the 39 PSS cases, lipogranulomas were found in the livers of 21 cases $(53.8 \%)$ (Table 2$)$. The lesion is an aggregation of cells containing lipid vacuoles and brown pigments in the cytoplasm. Lipogranulomas were randomly distributed in a hepatic lobule, and no pattern to the distribution was recognized in the present study.

According to the amount of lipid vacuoles and brown pig-

Table 2. Type and distribution of hepatic lipogranulomas, and histochemistry of cytoplasmic brown pigments in canine PSS cases

\begin{tabular}{|c|c|c|c|c|c|c|c|c|}
\hline \multirow{2}{*}{ Case No. } & \multirow{2}{*}{$\operatorname{sex}^{a)}$} & \multirow{2}{*}{ age $^{\text {b) }}$} & \multirow{2}{*}{ type } & \multirow{2}{*}{ distribution } & \multicolumn{4}{|c|}{ Cytoplasmic pigments $^{\mathrm{c})}$} \\
\hline & & & & & Berlin blue & Hall & PAS & Sudan black B \\
\hline 1 & M & $1 y$ & 1 & Scattered & + & - & + & + \\
\hline 2 & $\mathrm{MC}$ & $6 y 5 \mathrm{~m}$ & 1 & Portal area \& scattered & + & - & + & + \\
\hline 3 & $\mathrm{~F}$ & $2 \mathrm{y} 2 \mathrm{~m}$ & 1 & Scattered & - & - & + & + \\
\hline 4 & M & $1 \mathrm{y} 1 \mathrm{~m}$ & 1 & Scattered & + & - & + & + \\
\hline 5 & M & $2 \mathrm{y} 4 \mathrm{~m}$ & 1 & Portal area & - & - & - & + \\
\hline 6 & $\mathrm{~F}$ & $2 \mathrm{y} 1 \mathrm{~m}$ & 1 & Portal area & - & - & + & + \\
\hline 7 & $\mathrm{MC}$ & $2 \mathrm{y} 6 \mathrm{~m}$ & 1 & Portal area \& scattered & + & - & + & + \\
\hline 8 & M & $3 \mathrm{y} 6 \mathrm{~m}$ & 1 & Scattered & + & - & + & + \\
\hline 9 & M & $3 y \quad 10 \mathrm{~m}$ & 1 & Portal area & - & - & + & na \\
\hline 10 & $\mathrm{~F}$ & $3 y \quad 8 m$ & 1 & Scattered & - & - & + & + \\
\hline 11 & FS & $2 \mathrm{y} 10 \mathrm{~m}$ & $1 / 2$ & Portal area \& scattered & + & - & + & + \\
\hline 12 & $\mathrm{~F}$ & $4 y \quad 4 m$ & $1 / 2$ & Portal area \& scattered & + & - & + & + \\
\hline 13 & $\mathrm{MC}$ & $5 y \quad 7 m$ & 2 & Scattered & + & - & - & + \\
\hline 14 & M & $1 \mathrm{y} 5 \mathrm{~m}$ & 2 & Scattered & + & - & + & $+/-$ \\
\hline 15 & $\mathrm{~F}$ & $1 \mathrm{y} 2 \mathrm{~m}$ & 2 & Scattered & + & - & - & + \\
\hline 16 & FS & $2 \mathrm{y} 9 \mathrm{~m}$ & 2 & Scattered & + & - & + & + \\
\hline 17 & $\mathrm{~F}$ & $3 y \quad 10 \mathrm{~m}$ & 2 & Scattered & + & - & + & + \\
\hline 18 & $\mathrm{~F}$ & $2 \mathrm{y} 4 \mathrm{~m}$ & 2 & Scattered & + & - & + & + \\
\hline 19 & $\mathrm{~F}$ & $1 \mathrm{y} 7 \mathrm{~m}$ & 3 & Scattered & + & - & + & - \\
\hline 20 & M & $4 y \quad 11 \mathrm{~m}$ & 3 & Scattered & + & - & + & - \\
\hline 21 & $\mathrm{~F}$ & $1 \mathrm{y} 4 \mathrm{~m}$ & 3 & Scattered & + & - & + & na \\
\hline
\end{tabular}

a) F : female; FS : female spayed; $\mathrm{M}:$ male; $\mathrm{MC}:$ male castrated

b) $\mathrm{y}:$ years; $\mathrm{m}:$ months.

c) + : positive; +/-: weakly positive; -: negative; na : not assessed. 


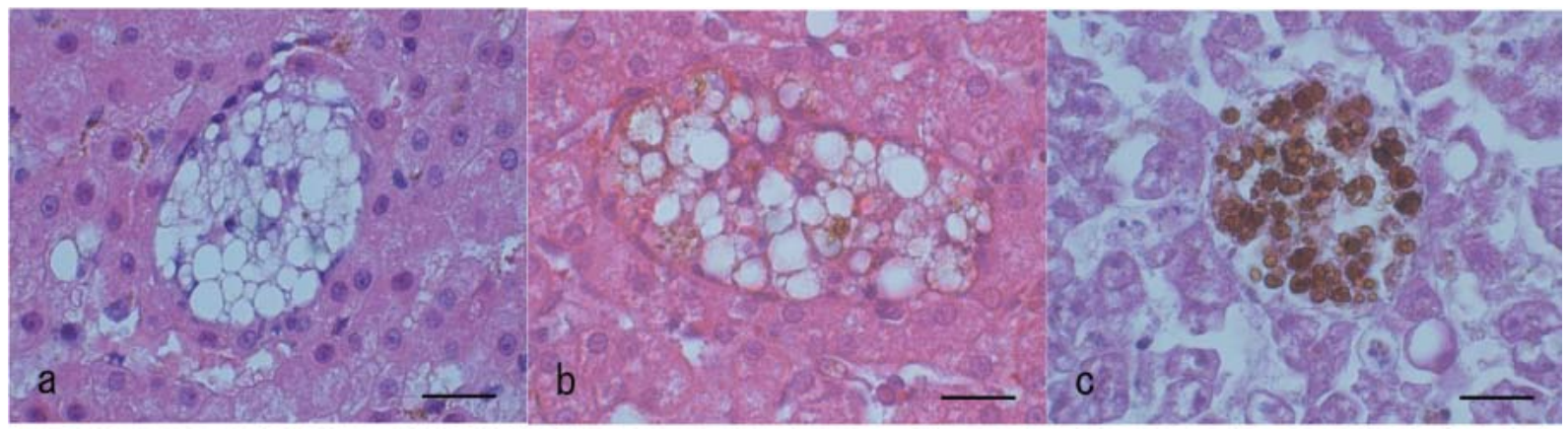

Fig. 1. Liver; dog. Hepatic lipogranulomas are grouped into 3 types; type 1 (a), type 2 (b), and type3 (c). HE stain. Bar=20 $\mu \mathrm{m}$.
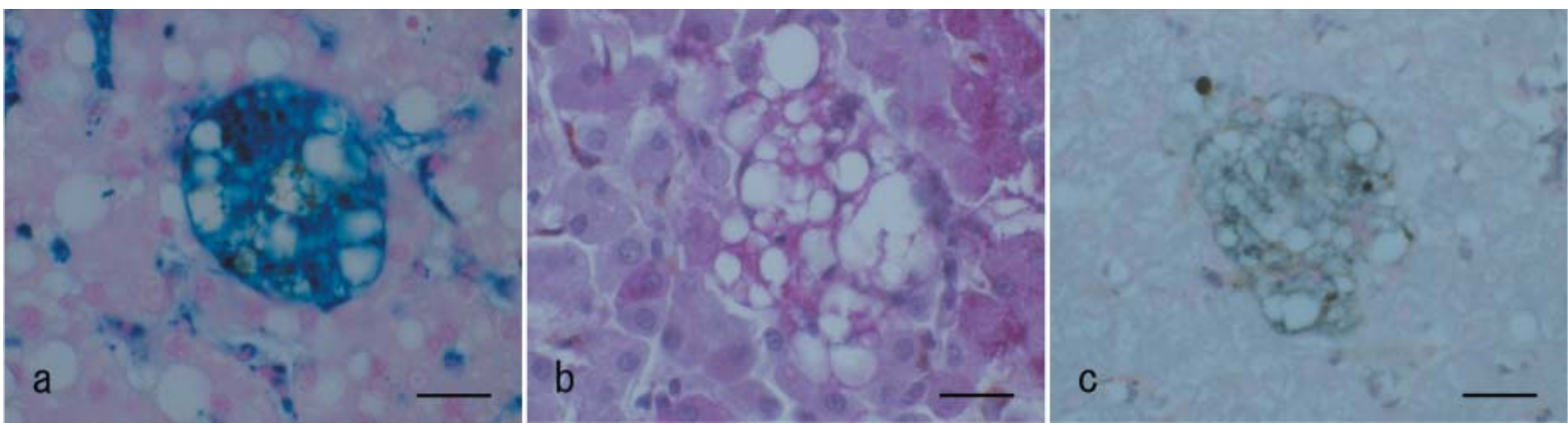

Fig. 2. Liver; dog. Cytoplasmic brown pigments in the lipogranuloma are stained blue with Berlin blue (a), red with the PAS reaction (b), and black with Sudan black B (c). Bar=20 $\mu \mathrm{m}$.
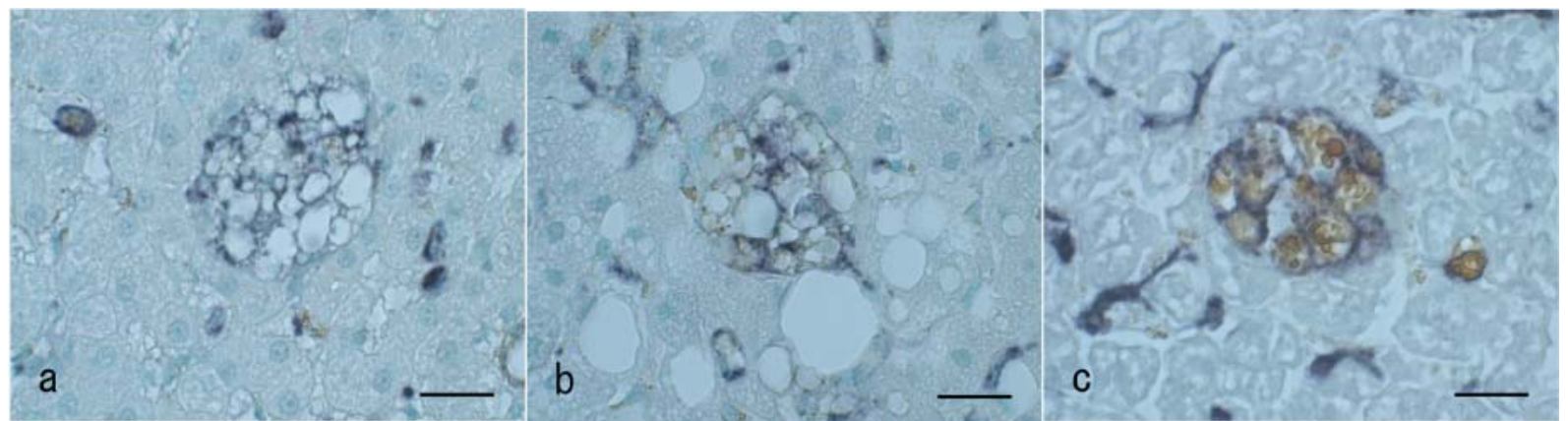

Fig. 3. Liver; dog. Lipogranulomas are positive for MSR-A: type 1 (a), type 2 (b), and type 3 (c). Immunohistochemistry for MSR-A. Bar $=20 \mu \mathrm{m}$.

ments in the cytoplasm, lipogranulomas were divided into 3 types (Fig. 1 a-c, Table 2). Type 1 is of a variety of sizes, and contains larger vacuoles and very few pigments. Type 3 is relatively small, and has few vacuoles and a lot of pigments. Type 2 is relatively small, and the amount of vacuoles and pigments is intermediate between that for type 1 and for type 3 . The 3 types of lipogranulomas were found in $35.9 \%$ (type 1 ), $53.8 \%$ (type 2), and $10.3 \%$ (type 3 ) of 36 PSS cases; and $0 \%$ (type 1), $44.7 \%$ (type 2), and $55.3 \%$ (type 3) of 37 non-PSS cases.

The pigments of all types were positively stained with Berlin blue, PAS, and Sudan black B (Fig. 2 a-c), but negative by the Hall method (Table 2).

Cells of all types of lipogranulomas showed a positive reaction for MSR-A with a cell-rimming pattern of $\mathrm{NiCl}_{2-}$ DAB color (Fig. $3 \mathrm{a}-\mathrm{c}$ ). Some vacuolated cells were positive for lysozyme, showing much the same pattern of staining as for MSR-A. Desmin was detected in some lipogranulomas though only a few vacuolated cells were positive in any of the 3 types (Fig. 4). Hepatocyte-antigen, albumin, and $\alpha$-SMA were not detected inside the lipogranulomas (data not shown).

Electron microscopy revealed that the small round cells making up the lesion had lysosome-like structures in the cytoplasm, indicating that the cells may originate from Kupffer cells and/or macrophages (Fig. 5). In addition, some of the cells contained electron-dense microgranular materials in the cytoplasm (Fig. 5). Such materials are con- 


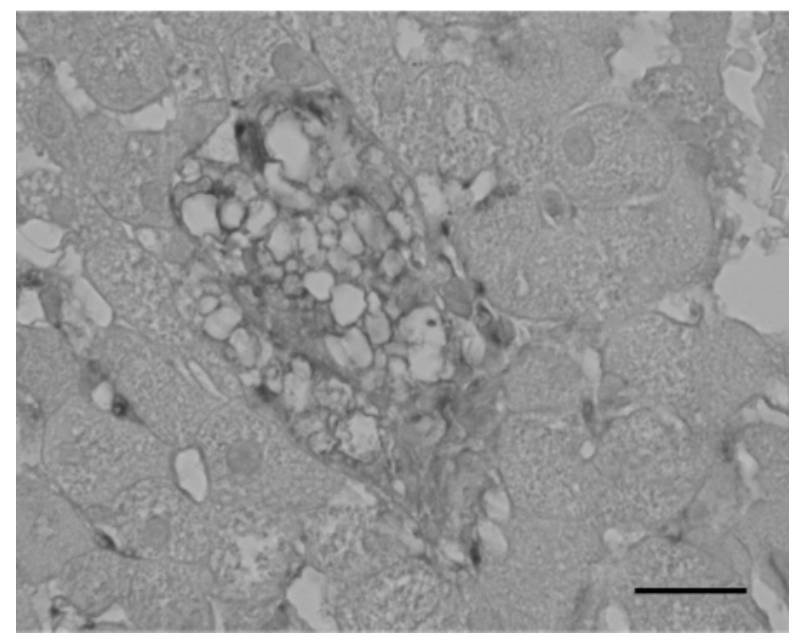

Fig. 4. Liver; dog. Some lipogranulomas are positive for desmin. Immunohistochemistry for desmin. Bar $=20 \mu \mathrm{m}$.

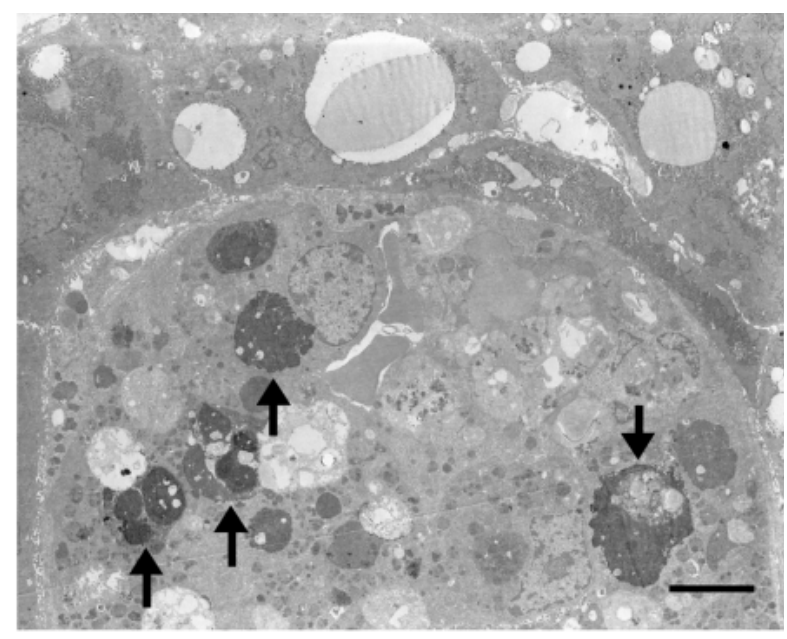

Fig. 5. Liver; dog. Electron micrograph of a lipogranuloma, showing an aggregation of small round cells with electrondense microgranular materials (arrows) in the cytoplasm. Bar $=5 \mu \mathrm{m}$.

sidered to be identical to the cytoplasmic brown pigments.

The incidence and number of lipogranulomas were compared between the PSS and non-PSS groups (Table 3). Lipogranulomas were found in 36/65 (55.4\%) of PSS cases, and $37 / 79(46.8 \%)$ of non-PSS cases, with no significant difference. Then we reestimated the incidence in dogs more than 1 year old, because most of the PSS cases were congenital [8], and if biopsied before 1 year of age, few lipogranulomas would be found. As a result, the incidence was 33/41 $(80.5 \%)$ in the PSS group, and $37 / 77(48.1 \%)$ in the nonPSS group. The difference was considered significant $(P<0.01)$.

Figure 6 shows the lipogranuloma density per definite area of the 2 groups. The density is also higher in the PSS group than non-PSS group $(P<0.01)$.

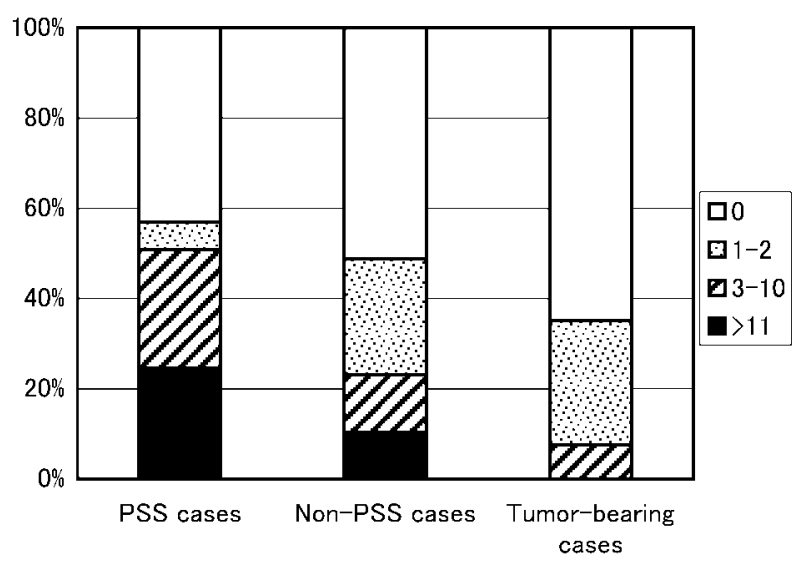

Fig. 6. The incidence and density of lipogranulomas in the liver of PSS and non-PSS cases. The density is presented as the total number of lipogranulomas $\square: 0, \square$ : $1-2$, 原: 3-10 and 11 per a definite area.

Table 3. The incidence of lipogranulomas

$\left.\begin{array}{lccccc}\hline \text { All cases } & \multicolumn{2}{c}{\text { Lipogranuloma }} & \text { Total } & \text { Incidence } \\ & + & - & & & \\ \hline \text { PSS group } & 36 & 29 & 65 & 55.4 \% & \\ \text { Non-PSS group } & 37 & 42 & 79 & 46.8 \% & \\ \hline \multicolumn{7}{c}{} \\ \hline \text { 1 year old } & \text { Lipogranuloma } & \text { Total } & \text { Incidence } \\ \hline \multicolumn{7}{c}{+} \\ \hline \text { PSS group } & 33 & 8 & 41 & 80.5 \% & \square * \\ \text { Non-PSS group } & 37 & 40 & 77 & 48.1 \% & \end{array}\right]$

* : Significantly different $(P<0.01)$.

\section{DISCUSSION}

Lipogranulomas are described in textbooks of veterinary medicine as one of the histopathological changes in canine livers with PSS [4]. Similar lesions are observed in the rat as well as in human livers with cirrhosis $[5,6,9,10]$. Additionally, human "sclerosing lipogranulomas" occur in the subcutaneous fat tissues of the genital region, buttocks, and extremities and in the orbit $[1,11,17,19]$. Regarding canine PSS, however, a detailed histopathological characterization has not been made. In the present study, we therefore examined the histopathological characteristics of hepatic lipogranulomas in canine PSS cases.

Lipogranulomas were defined as lesions consisting of small round cells which contain lipid vacuoles and brown pigments in their cytoplasm, though the amount of vacuoles and pigments varied among lesions. We, therefore, grouped the lesions into 3 types according to the amount of vacuoles and pigments. Then, the percentages of each type in the PSS and non-PSS groups were determined. Type 1 was observed only in the PSS group, while type 3 was observed frequently in the non-PSS group. In non-PSS group, no specific lesions of the liver were found in relation to the formation of 
lipogranulomas. Here, we can propose two hypotheses regarding the relations among the 3 types. One is that type 1 changes into type 2 and 3 with the development of the lesion. The other is that each type is independently formed. If the former hypothesis is true, there should be more variety of lipogranuloma types in one slide or in one group. However, we obtained no such evidence in the present study. Though no positive proof of either hypothesis can be presented, it is likely that the latter hypothesis is closer to the truth. To clarify this point, the origin of brown pigments in the lipogranuloma should be analyzed.

A previous study demonstrated that the cytoplasmic brown pigments are hemosiderin and ceroid (or lipofuscin), as confirmed in the present study of PSS cases [18]. We speculate that a microcirculatory disturbance in the PSS liver would result in the abnormal metabolism of iron and lipid as suggested by the WSAVA working group [21]. Furthermore, it is already established that more iron accumulates in human patients who have undergone PSS than in non-PSS patients [3]. An increased absorption of iron at the duodenum in canine PSS cases was indicated in some experimental studies [7]. Iron accumulation is believed to be involved in increased oxidative stress with the iron-catalyzed production of reactive oxygen species causing oxidative damage to lipids, proteins, and other molecules [3, 20]. Thus ceroid may secondarily accumulate in the liver. Therefore, the brown ceroid pigments in the lipogranulomas of the liver in dogs with PSS is speculated to originate from degenerative hepatocytes. However, albumin/hepatocytepositive cells were not detected inside any lipogranulomas. In addition, few degenerative changes to hepatocytes were observed around any of the lipogranulomas. It is therefore unlikely that ceroid pigments simply originate from degenerative hepatocytes.

Given the results of immunostaining, it is likely that both MSR-A and lysozyme indicate phagocytes, for the staining pattern of the two antibodies was very similar. Accordingly, it is highly possible that Kupffer cells and/or macrophages but not hepatocytes are mainly involved in the formation of lipogranulomas. The report by WSAVA mentioned that the main cell components of lipogranulomas are macrophages [21]. Considering the events, the cytoplasmic brown ceroid pigments of the lipogranulomas might be derived not only from degenerative hepatocytes, but also from sinusoidal blood. Ito cells (hepatic stellate cells) were ruled out as a candidate for a component of lipogranulomas. This is because desmin-positive cells were scarce and considered to have been incidentally trapped in the lipogranulomas.

Next, the reason the incidence of lipogranulomas in PSS cases was higher among the dogs more than 1 year old was taken into consideration. The time required for a lipogranuloma to form may be a factor given that few hepatic lipogranulomas were found before 1 year of age. That is to say, even though in all PSS cases there is the potential for lipogranulomas to form, the process might take at least 1 year.

As mentioned above, lipogranulomas are considered to be involved in hepatic cirrhosis in human medicine $[9,10]$. Although canine PSS can also be considered a cause of hepatic cirrhosis, the significance of lipogranulomas in the pathogenesis of cirrhosis is not clear. In cases of cirrhosis, degenerative changes to hepatocytes can lead to fibrogenesis, though the hepatic lipogranulomas in dogs with PSS seem to have no correlation with hepatocytic degeneration. This point is very important when considering the prognosis of hepatic change in canine PSS cases. Therefore, further study should be performed to clarify this point.

In this study, we histopathologically examined the hepatic lipogranulomas in dogs with PSS and grouped them into 3 types according to the amount of cytoplasmic lipid vacuoles and brown pigments. The cytoplasmic brown pigments were considered to be ceroid and hemosiderin. Immunohistochemistry and electron microscopy revealed that phagocytes (Kupffer cells and/or macrophages) would be involved as the main component in all types of lipogranulomas. The incidence of hepatic lipogranuloma was higher in PSS cases than non-PSS cases among the animals that were more than 1 year old. The pathogenesis of lipogranuloma in dogs with PSS remains to be clarified.

\section{REFERENCES}

1. Abel, A. D., Carlson, J. A., Bakri, S. and Meyer, D. R. 2003. Sclerosing lipogranuloma of the orbit after periocular steroid injection. Ophthalmology 110: 1841-1845.

2. Baade, S., Aupperle, H., Grevel, V. and Schoon, H. A. 2006. Histopathological and immunohistochemical investigations of hepatic lesions associated with congenital portosystemic shunt in dogs. J. Comp. Pathol. 134: 88-90.

3. Bonkovsky, H. L., Lambrecht, R. W. and Shan, Y. 2003. Iron as a co-morbid factor in nonhemochromatotic liver disease. Alcohol. 30: 137-144.

4. Borrows, C. F. 2003. Liver disorders. pp. 337-349. In: Clinical Medicine of the Dog and Cat, 1st ed, (Schaer, M. ed.), Veterinary Press, London, England.

5. Christoffersen, P., Braendstrup, O., Juhl, E. and Poulsen, H. 1971. Lipogranulomas in human biopsies with fatty change. A morphological, biochemical and clinical investigation. Acta. Pathol. Microbiol. Scand [A]. 79: 150-158.

6. Delladetsima, J. K., Horn, T. and Poulsen, H. 1987. Portal tract lipogranulomas in liver biopsies. Liver. 7: 9-17.

7. Doberneck, R. C., Fischer, R. and Smith, D. 1975. Gastrojejunostomy inhibits postshunt siderosis. Surgery 78: 334-338.

8. Fossum, T. W. 2002. Surgery of the liver. pp. 450-474. In: Small Animal Surgery, 2nd ed. (Fossum, T. W. ed.), Mosby, Saint Louis, U.S.A.

9. Hartroft, W. S. 1950. Accumulation of fat in liver cells and in lipodiastaemata preceding experimental dietary cirrhosis. Anat. Rec. 106: 61-87.

10. Hartroft, W. S. 1953. Diagnostic significance of fatty cysts in cirrhosis. AMA. Arch. Pathol. 55: 63-69.

11. Hohaus, K., Bley, B., Köstler, E., Schönlebe, J. and Wollina, U. 2003. Mineral oil granuloma of the penis. J. Eur. Acad. Dermatol. Venereol. 17: 585-587.

12. Hsu, S. M. and Soban, E. 1982. Color modification of diaminobenzidine (DAB) precipitation by metallic ions and its application for double immunohistochemistry. J. Histochem. 
Cytochem. 30: 1079-1082.

13. Kelly, W. R. 1993. The liver and biliary system. pp. 319-406. In: Pathology of Domestic Animals, 4th ed., vol. 2. (Jubb, K. V,. Kennedy, P. C. and Palmer, N eds.), Academic Press, San Diego, U.S.A.

14. Merchenthaler, I., Stankovics, J. and Gallyas, F. 1989. A highly sensitive one-step method for silver intensification of the nickel-diaminobenzidine endproduct of peroxidase reaction. J. Histochem. Cytochem. 37: 1563-1565.

15. Meyer, D. J. 1996. Hepatic pathology. pp. 633-653. In: Strombeck's Small Animal Gastroenterology, 3rd ed. (Guilford, W. G., Center, S. A., Strombeck, D. R., Williams, D. A. and Meyer, D. J. eds.), W. B. Saunders, Philadelphia, U.S.A.

16. Meyer, D. J. and Harvey, J. W. 1994. Hematologic changes associated with serum and hepatic iron alterations in dogs with congenital portosystemic vascular anomalies. J. Vet. Intern. Med. 8: 55-56.
17. Ricchiuti, V. S., Richman, M. B., Haas, C. A., Desai, D. and Cai, D. X. 2002. Sclerosing lipogranuloma of the testis. Urology. 60: 515.

18. Seehafer, S. S. and Pearce, D. A. 2006. You say lipofuscin, we say ceroid: defining autofluorescent storage material. Neurobiol. Aging. 27: 576-588.

19. Smetana, H. F. and Bernhard, W. 1950. Sclerosing lipogranuloma. Arch. Pathol. 50: 296-325.

20. Terman, A. and Brunk, U. T. 2004. Lipofuscin. Int. J. Biochem. Cell. Biol. 36: 1400-1404.

21. Winkle, T. V., Collen, J. M., van den Ingh, T. S. G. A. M., Charles, J.A. and Desmet, V. J. 2006. Morphological classification of parenchymal disorders of the canine and feline liver. pp. 103-116. In: WSAVA Standards for Clinical and Histological Diagnosis of Canine and Feline Liver Disease, 1st ed. (WSAVA Liver Standardization Group. ed.), Elsevier Limited, Oxford, England. 